\title{
Variação temporal no sítio de vocalização em uma comunidade de anuros de Botucatu, Estado de São Paulo, Brasil
}

\author{
Geise Valentina de Melo ${ }^{1,3}$, Denise de Cerqueira Rossa-Feres ${ }^{1}$ \& Jorge Jim ${ }^{2}$
}

Biota Neotropica $v 7$ (n2) - http://www.biotaneotropica.org.br/v7n2/pt/abstract?article+bn01707022007

\author{
Recebido em 20/10/06 \\ Versão reformulada recebida em 29/03/07 \\ Publicado em 01/05/07
}

${ }^{1}$ Departamento de Zoologia e Botânica, IBILCE-UNESP, Rua Cristovão Colombo, Jardim Nazareth, São José do Rio Preto, SP, Brasil, www.ibilce.unesp.br

${ }^{2}$ Departamento de Zoologia, Instituto de Biociências, UNESP, Rubião Jr.,

Botucatu, SP, Brasil, www.ibb.unesp.br

${ }^{3}$ Autor para correspondência: Geise Valentina de Melo, e-mail: geisevm@uol.com.br

\begin{abstract}
Melo, G.V., Rossa-Feres, D.C. \& Jim, J. Temporal variation in calling site use in a community of anurans in Botucatu, São Paulo State, Brazil. Biota Neotrop. May/Aug 2007 vol. 7, no. 2 http://www.biotaneotropica. org.br/v7n2/pt/abstract?article+bn01707022007 ISSN 1676-0603.

A study on temporal variation in calling site use in a community of anurans was carried out in a permanent pond, between October of 1996 and February of 1998, in southeastern Brazil. Fourteen species of anurans were registered, belonging to the families: Hylidae, Leptodactylidae, Leiuperidae, and Bufonidae. Most species in the community were accidental $(n=6)$ and the majority vocalized in the hot and humid months (October to February). A sucessional pattern in time distribution and a significant statistical correlation between the richness and climatic variables was observed. However, significant statistical correlation between monthly abundance and climatic variables was found only for four species. The analysis of niche breadth, given by the Index of Levins, indicated that the majority of the species was specialist in the use of the two considered resources. The Coefficient of Similarity of Morisita-Horn did not point overlap in time occurrence, but a high overlap in calling site use was detected. Multidimensional overlap showed intermediate values between studied dimensions.

Keywords: community ecology, resource partitioning, multidimensional niche, anurans, southeastern Brazil.

\section{Resumo}

Melo, G.V., Rossa-Feres, D.C. \& Jim, J. Variação temporal no sítio de vocalização em uma comunidade de anuros de Botucatu, Estado de São Paulo, Brasil. Biota Neotrop. May/Aug 2007 vol. 7, no. 2 http://www. biotaneotropica.org.br/v7n2/pt/abstract?article+bn01707022007 ISSN 1676-0603.

Um estudo da variação temporal no sítio de vocalização de uma comunidade de anuros foi realizado em uma poça permanente, entre outubro de 1996 e fevereiro de 1998, em Rubião Jr. município de Botucatu, São Paulo. Foram registradas 14 espécies de anuros pertencentes às famílias Hylidae, Leptodactylidae, Leiuperidae e Bufonidae. A comunidade apresentou um maior número $(n=6)$ de espécies de ocorrência acidental $(n<20 \%)$ e maior riqueza de espécies e número de machos em atividade de vocalização nos meses quentes e úmidos (outubro a fevereiro). Foi observado um padrão sucessional na distribuição temporal das espécies e correlação significativa entre a riqueza e as variáveis climáticas, mas, apenas quatro espécies tiveram a abundância mensal correlacionada com estas variáveis. A grande maioria das espécies teve pequena amplitude de nicho, sendo consideradas especialistas no uso dos dois recursos considerados (ocorrência temporal e sítio de vocalização), não havendo sobreposição na ocorrência temporal, mas com alta sobreposição na ocupação de sítios de vocalização. A sobreposição no nicho multidimensional foi intermediária entre a duas dimensões consideradas, demonstrando complementaridade de nicho.
\end{abstract}

Palavras-chave: ecologia de comunidades, partilha de recursos, nicho multidimensional, anuros, sudeste do Brasil. 


\section{Introdução}

Segundo Putman (1994) a posição de um organismo dentro de uma comunidade pode ser definida em termos do seu padrão de utilização de recursos, e sua interação com outros organismos em relação ao uso desses mesmos recursos. Tal explicação sobre a posição de um organismo numa comunidade e suas relações com outros organismos expressa o conceito de nicho ecológico (Putman 1994).

Comunidades de anuros brasileiros foram estudadas na região Amazônica (e.g. Crump 1971, Gascon 1991, Neckel-Oliveira et al. 2000), na Mata Atlântica (e.g. Heyer et al. 1990, Haddad \& Sazima 1992, Bertoluci 1998, Conte \& Rossa-Feres 2006), e, em áreas abertas do sudeste do Brasil (e.g. Cardoso et al., 1989, Rossa-Feres \& Jim 1994 e 2001, Vasconcelos \& Rossa-Feres 2005). De modo geral, na região neotropical, a maioria das espécies de anuros apresenta atividade reprodutiva no período quente e úmido do ano (e.g. Duellman \& Trueb 1994, Donelly \& Guyer 1994, Rossa-Feres \& Jim 1994), sendo essa atividade fortemente influenciada pela ocorrência de chuvas (Aichinger, 1987; Gascon 1991). Dada a grande diversidade de anuros nessa região, em muitas comunidades observa-se grande número de indivíduos de diferentes espécies, com diferentes graus de parentesco, ocupando os mesmos corpos d'água. Assim, torna-se importante compreender os mecanismos que possibilitam às espécies de uma comunidade ocupar o mesmo ambiente, na mesma época do ano.

Morris (1990) ressalta que uma completa compreensão da estrutura de qualquer comunidade é possível somente no contexto da variação espacial e temporal. Muitos estudos recentes demonstram a influência da distribuição espacial e temporal na estrutura de comunidades de anuros brasileiros (e.g. Rossa-Feres \& Jim, 1994 e 2001, Eterovick \& Sazima 2000). Os estudos de ocupação de microambientes são particularmente importantes em comunidades de anuros de área aberta já que, nestes locais, a heterogeneidade estrutural é freqüentemente muito baixa e a semelhança estrutural entre os corpos d'água é grande.

Este trabalho teve como objetivos determinar os padrões de distribuição temporal e uso do ambiente pelas espécies de uma poça permanente, e determinar a influência destas duas dimensões do nicho na estrutura de uma comunidade de anuros.

\section{Material e Métodos}

\section{1. Área e corpo d'água estudado}

O município de Botucatu, localizado na região centro-oeste do estado de São Paulo, possui clima subtropical úmido (CWA Koeppen), com estação chuvosa estendendo-se de outubro a março e estação seca, de abril a setembro. Segundo Kronka et al. (1998), a região possui cerca de 4.500 ha de área remanescente de cerrado e "cerradão". O Distrito de Rubião Jr., Botucatu, está localizado na parte superior da "cuesta", a cerca de $900 \mathrm{~m}$ de altitude.

As amostragens foram realizadas em poça artificial permanente com margens em barranco, situada em uma área de pastagem, localizada na área urbana do distrito de Rubião Jr. A poça possui margens em barranco e cerca de $20 \mathrm{~m}$ de comprimento, com 9,60 m na sua parte mais estreita e $14,50 \mathrm{~m}$ na sua parte mais larga; a profundidade máxima é de cerca de 1,20 m. Apresenta vegetação arbustiva (Onagraceae, Solanaceae, Verbenaceae, Rutaceae e Asteraceae) na região marginal, Poaceae que ocorre nas margens e adentra o corpo d'água, e Thyphaceae que ocorre somente no interior da poça. Por uma das margens há constante e discreta entrada de água proveniente de uma nascente. Na margem oposta, existe um estreito canal por onde a água é escoada, descendo através do barranco que separa a poça de um brejo. Este brejo estende-se até um córrego, cujas margens possuem vegetação arbustiva e arbórea.

\section{Amostragens e análise de dados}

As visitas à área de estudo tiveram periodicidade quinzenal, totalizando 31 noites de observação, no período de outubro de 1996 a fevereiro de 1998. As observações foram iniciadas logo após o pôr do sol e encerradas por volta de 22:00 horas. As temperaturas do ar e da água foram determinadas sempre ao início e ao final de cada coleta. Os dados de pluviosidade mensal foram obtidos no Departamento de Ciências Ambientais da Fazenda Experimental Lageado da UNESP/Botucatu, distante aproximadamente $8 \mathrm{~km}$ do local estudado. Para a visualização dos adultos foi utilizada lanterna de luz branca. Para cada indivíduo encontrado foi registrada a altura na vegetação (espécies de hábito trepador) ou profundidade (espécies de hábito semi-aquático) e a distância da margem, em direção ao centro ou externamente à poça, utilizando-se uma trena.

A altura média de empoleiramento na vegetação foi comparada pelo teste t de Student para pares de espécies, a um nível de significância de 5\% (Vieira, 1985). Além disso, o uso de sítio de vocalização foi analisado em relação ao tamanho dos indivíduos. Para isso, foram considerados de pequeno porte anuro com comprimento total até $25 \mathrm{~mm}$, de médio porte aqueles com comprimento total entre $25,1 \mathrm{e}$ $50 \mathrm{~mm}$, e de grande porte os anuros com comprimento total superior a $51 \mathrm{~mm}$. A influência das variáveis ambientais (temperaturas do ar e da água e pluviosidade) sobre a riqueza mensal e a abundância das espécies foi verificada através do coeficiente de correlação de Kendall, a um nível de significância de $5 \%$.

A constância de ocorrência das espécies (C) da comunidade foi determinada segundo o índice de Dajoz (1973), sendo as espécies classificadas como constantes quando $\mathrm{C} \geq 50 \%$, acessórias quando $25 \%<\mathrm{C}<50 \%$ e acidentais quando $\mathrm{C} \leq 25 \%$. A amplitude de nicho foi calculada pelo Índice de Levins (B), que dá um maior peso aos recursos abundantes (Krebs 1999). Para facilitar a interpretação do resultado foi feita a padronização de Hurlber (Krebs 1999). As espécies com valores de amplitude de nicho entre 0 e 0,50 foram consideradas especialistas; aquelas com valores entre 0,51 e 0,70 foram consideradas intermediárias e as com valores entre 0,71 e 1,0 foram consideradas generalistas.

A sobreposição em cada dimensão do nicho (tempo e sítio de vocalização) e a sobreposição multidimensional foram calculadas pela aplicação do Índice de Similaridade de Morisita-Horn $\left(\mathrm{C}_{\mathrm{H}}\right)$ (Krebs 1999). Para verificar o grau de sobreposição entre as espécies dos agrupamentos evidenciados, o mesmo índice de similaridade foi aplicado para pares de espécies. Foram considerados agrupamentos de espécies com alta sobreposição aqueles com $\mathrm{C}_{\mathrm{H}} \geq 0,71$, com sobreposição parcial aqueles com $\mathrm{C}_{\mathrm{H}}$ entre 0,51 e 0,70 , e com baixa sobreposição os agrupamentos com $\mathrm{C}_{\mathrm{H}} \leq 0,50$. O coeficiente de correlação cofenético (r) foi determinado para verificar a representatividade das matrizes de similaridade nos dendrogramas, sendo considerados com alta representatividade os dendrogramas com valores de $r \geq 0,8$.

\section{Resultados}

\section{Ocorrência temporal}

Foram registradas 14 espécies pertencentes a seis gêneros de três famílias de anuros: Hylidae (nove espécies), Leptodactylidae (duas espécies), Leiuperidae (duas espécies) e Bufonidae (uma espécie) (Tabela 1). A comunidade estudada pode ser caracterizada por apresentar um maior número de espécies acidentais $(n=8)$ e poucas espécies constantes $(\mathrm{n}=3)$ e acessórias $(\mathrm{n}=3)$ (Tabela 1). Hypsiboas prasinus, H.faber, Eupemphix nattereri e Leptodactylus labyrinthicus 
Tabela 1. Freqüência de ocorrência, amplitude de nicho para a dimensão sazonalidade (B) e valores de correlação (r) entre a abundância e variáveis climáticas para 14 espécies de anuros registradas em 31 amostragens, realizadas em uma poça permanente em Rubião Jr., Botucatu, SP. $\mathrm{n}$ total $=$ número de indivíduos, con $=$ constante, ace $=$ acessória, aci $=$ acidental; $\mathrm{B}=$ índice de Levins; $*$ indica espécie considerada generalista; Tar = temperatura do ar; Tag = temperatura da água; entre parênteses estão os valores de significância; - = espécie com ocorrência única, para a qual amplitude de nicho e correlação não foram calculadas.

Table 1. Frequency of occurrence, niche breadth for seasonality (B) and values of correlation (r) with climatic variables for 14 species of anurans registered in 31 samplings, carried out in a permanent pond in Rubião Jr, Botucatu, SP. $\mathrm{n}$ total = individual number, con $=$ constant, ace $=$ accessory, aci $=$ accidental; $\mathrm{B}=$ Levins index; * it indicates species generalist; Tar = air temperature; Tag = water temperature; values of significance in parentheses; - = species with only one occurrence, for which niche breadth and correlation had not been calculated.

\begin{tabular}{|c|c|c|c|c|c|c|}
\hline & n total & Freqüiência & B-saz & r-Tar & r-Tag & r-Plu \\
\hline Dendropsophus minutus & 342 & 90,32 con & $0,74 *$ & $0,51(0,002)$ & $0,74(0,0001)$ & $0,07(0,35)$ \\
\hline D. nanus & 186 & $51,61 \mathrm{con}$ & 0,25 & $0,60(0,0004)$ & $0,44(0,01)$ & $0,33(0,03)$ \\
\hline D. sanborni & 32 & 45,16 ace & 0,32 & $0,33(0,03)$ & $0,33(0,04)$ & $0,35(0,02)$ \\
\hline D. elianeae & 5 & 12,9 aci & 0,16 & - & - & - \\
\hline Hypsiboas albopunctatus & 28 & 35,48 ace & 0,21 & $0,00(0,50)$ & $0,21(0,28)$ & $0,28(0,22)$ \\
\hline H.. caingua & 20 & 19,35 aci & 0,09 & $-0,33(0,70)$ & $0,33(0,30)$ & $-1,00(0,95)$ \\
\hline H. prasinus & 1 & 3,23 aci & - & - & - & - \\
\hline H. faber & 3 & 6,45 aci & 0,05 & - & - & - \\
\hline Scinax fuscovarius & 13 & 16,13 aci & 0,09 & $0,33(0,30)$ & $0,33(0,30)$ & $-0,33(0,70)$ \\
\hline Physalaemus cuvieri & 111 & 58,06 con & 0,37 & $0,44(0,01)$ & $0,36(0,03)$ & $0,24(0,08)$ \\
\hline Eupenphix nattereri & 1 & 3,23 aci & - & - & - & - \\
\hline Chaunus .ictericus & 28 & 45,16 ace & 0,37 & $-0,17(0,84)$ & $-0,29(0,94)$ & $0,00(0,50)$ \\
\hline Leptodactylus ocellatus & 5 & 12,9 aci & 0,25 & - & - & - \\
\hline L. labyrinthicus & 3 & 6,45 aci & 0,05 & - & - & - \\
\hline
\end{tabular}

foram raras, com apenas um a três exemplares registrados durante o período de estudo (Tabela 1).

A maior riqueza de espécies foi registrada nos meses de outubro a fevereiro, quando a temperatura do ar foi superior a $19{ }^{\circ} \mathrm{C}$ e a pluviosidade superior a $100 \mathrm{~mm}^{3}$ (Figura 1). Consequentemente, verificou-se correlação positiva significativa entre o número de espécies vocalizando e a pluviosidade mensal $(r=0,31, p=0,04)$, temperatura do ar $(\mathrm{r}=0,54, \mathrm{p}=0,001)$ e temperatura da água $(\mathrm{r}=$ $0,64, \mathrm{p}=0,0004)$. Outubro foi o mês de maior riqueza nos dois anos estudados, com nove espécies registradas em cada ano. Destas, sete estavam presentes em ambos os anos (Figura 1). Dendropsophus minutus foi a única espécie generalista quanto à ocorrência sazonal, mas sua abundância foi maior nos meses mais quentes, sendo significativamente correlacionada com as temperaturas do ar e da água. A abundância de Dendropsophus nanus e de D. sanborni foi significativamente correlacionada com as três variáveis climáticas consideradas, assim como a abundância de Physalaemus cuvieri com as temperaturas do ar e da água. Já a abundância das demais espécies não foi correlacionada com nenhuma das variáveis ambientais consideradas (Tabela 1 e Figura 1).

As abundâncias de Dendropsophus nanus e de D. sanborni variaram inversamente de modo que, no mês de maior abundância da primeira (dezembro de 1997) não foi coletado nenhum indivíduo da segunda (Figura 1).

A análise de agrupamento evidenciou duas guildas: 1) P. cuvieri, $D$. nanus e D. elianeae, que ocorreram principalmente nos meses de novembro e dezembro e 2) L. ocellatus, D. sanborni e D. minutus que ocorreram principalmente em fevereiro, outubro e novembro (Figura 2). De modo geral, as três espécies da primeira guilda apresentaram alta sobreposição de nicho, enquanto apenas uma das três possíveis combinações de pares de espécies da segunda guilda apresentou alta sobreposição de nicho. Exceto a alta sobreposição entre P. cuvieri e L. ocellatus, a sobreposição entre as demais espécies foi parcial ou baixa tanto entre pares de espécies congenéricas quanto entre espécies de gêneros e famílias diferentes (Tabela 2). Dentre as
66 combinações de pares de espécies possíveis, $12(18,2 \%)$ apresentaram total segregação sazonal ou valores de sobreposição muito próximos a zero e, $27(40,9 \%)$ espécies apresentaram valores de sobreposição inferiores a 0,50 (Tabela 2).

\section{Sítio de vocalização}

A maioria dos indivíduos das quatro espécies de hilídeos pequenos ocorreu no interior da poça. Dentre eles, machos de $D$. minutus ocuparam sítios de vocalização mais baixos, sendo a maioria $(70,2 \%$, $\mathrm{n}=165$ ) encontrada sobre o solo (Figura 3, Tabela 3). Alguns indivíduos de $D$. nanus $(22 \%, \mathrm{n}=10)$ e de $D$. sanborni $(17,6 \%, \mathrm{n}=3)$ também ocorreram sobre o solo, mas a grande maioria $(D$. nanus $=48,9 \%$, $\mathrm{n}=22 ;$ D. sanborni $=76,5 \%, \mathrm{n}=13$ ) foi encontrada empoleirada entre 10 e $40 \mathrm{~cm}$ de altura. Dendropsophus nanus foi a espécie que ocupou sítios de vocalização mais altos, sendo $28,9 \%$ dos indivíduos encontrados entre 41 e $70 \mathrm{~cm}$ de altura (Figura 3, Tabela 3). Os poucos indivíduos de $D$. elianeae $(\mathrm{n}=3)$ observados estavam empoleirados entre 7 e $53 \mathrm{~cm}$ de altura (Figura 3 ).

Dentre os hilídeos maiores, machos de Scinax fuscovarius foram observados somente sobre o solo, no máximo a $1 \mathrm{~m}$ de distância do corpo d'água. A maioria dos indivíduos de $H$. caingua $(61,9 \%, \mathrm{n}=13)$ e de $H$. albopunctatus $(61,1 \%, \mathrm{n}=11)$ também ocorreu externamente ao corpo d'água, sendo que alguns machos vocalizaram sobre o solo, porém a maioria $(66,7 \%$ e $55 \%$, respectivamente) vocalizou empoleirada entre 20 e $50 \mathrm{~cm}$ de altura (Figura 4). Foram observados dois indivíduos de $H$. faber no interior da poça, flutuando em locais com profundidade de 7 e $40 \mathrm{~cm}$.

Todos os indivíduos de $C$. ictericus ocorreram sobre solo seco ou encharcado, sendo que a metade deles vocalizou no interior da poça e a outra metade, no máximo a 1,5 m do corpo d'água (Figura 5). A maioria dos indivíduos de Physalaemus cuvieri $(88,6 \%, \mathrm{n}=62)$ foi encontrada no interior da poça, em "pocinhas" com profundidade máxima de $10 \mathrm{~cm}$. Tanto L. ocellatus (Figura 5), quanto L. labyrinthicus foram encontrados no interior da poça, em locais com profundidade superior a $5 \mathrm{~cm}$. 

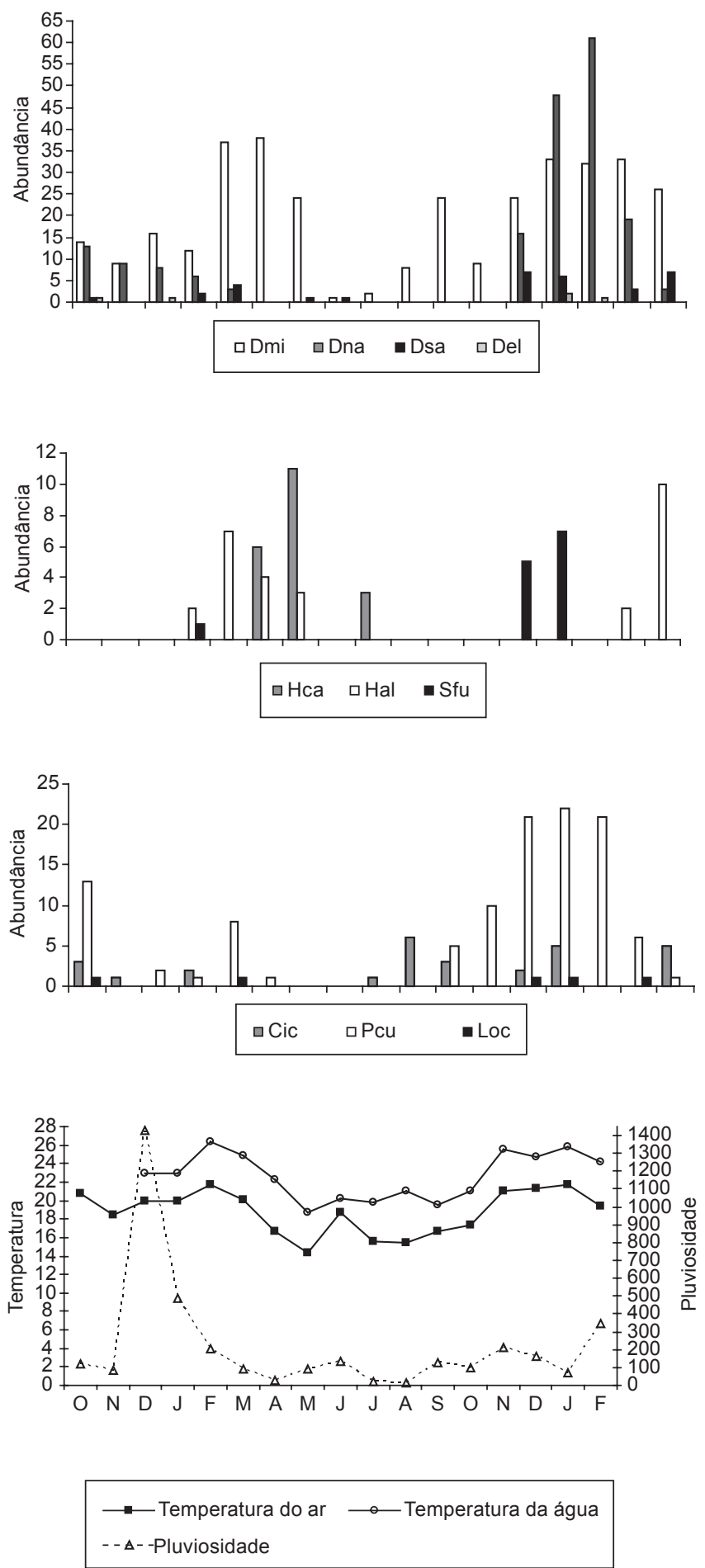

Figura 1. Abundância mensal das 14 espécies de anuros registradas em poça permanente e variáveis climáticas registradas em Botucatu, SP $($ Dmi $=$ Dendropsophus minutus, Dna $=D$. nanus, Dsa $=S$. sanborni, Del $=$ D. elianeae $; \mathrm{Hca}=$ Hypsiboas caingua, $\mathrm{Hal}=H$. albopunctatus, $\mathrm{Sfu}=$ Scinax fuscovarius $; \mathrm{Cic}=$ Chaunus ictericus, $\mathrm{Pcu}=$ Physalaemus cuvier $;$ Loc $=$ Leptodactylus ocellatus $)$.

Figure 1. Monthly abundance of the 14 species of anurans registered in a permanent pond and climatic variables registered in Botucatu, SP $($ Dmi $=$ Dendropsophus minutus, Dna $=D$. nanus, Dsa $=S$. sanborni, $\mathrm{Del}=$ D. elianeae $; \mathrm{Hca}=$ Hypsiboas caingua, $\mathrm{Hal}=H$. albopunctatus, $\mathrm{Sfu}=$ Scinax fuscovarius $; \mathrm{Cic}=$ Channus ictericus, $\mathrm{Pcu}=$ Physalaemus cuvieri $;$ Loc $=$ Leptodactylus ocellatus .

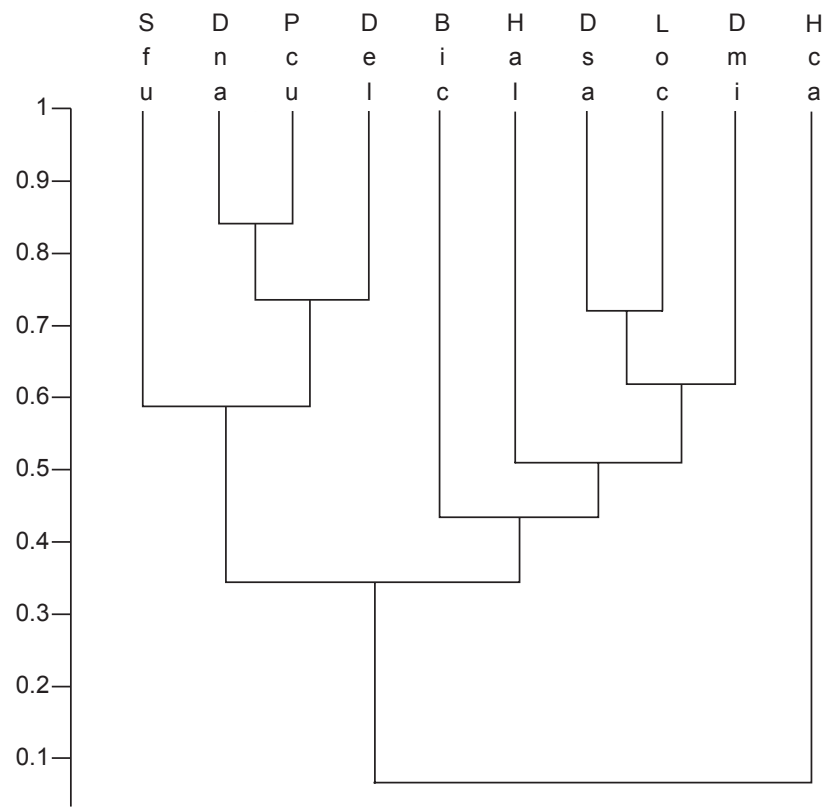

Figura 2. Similaridade (índice de Morisita-Horn) na ocorrência sazonal das 10 espécies mais abundantes de anuros registradas em uma poça permanente em Rubião Jr., Botucatu, SP, no período de outubro de 1996 a fevereiro de 1998. $($ Dmi $=$ D. minutus $;$ Dna $=$ D. nanus $;$ Dsa $=$ D. sanborni $;$ Del $=$ D. elianae $;$ $\mathrm{Hca}=H$. caingua $; \mathrm{Hal}=H$. albopunctatus $; \mathrm{Sfu}=$ Scinax fuscovariu $;$ Cic $=$ Chaunus ictericus $; \mathrm{Pcu}=$ Physalaemus cuvieri $;$ Loc $=$ Leptodactylus ocellatus).

Figure 2. Similarity (Morisita-Horn index) in the sazonal occurrence of the 10 more abundant species of anurans registered in a permanent pond in Rubião Jr, Botucatu, SP, from October 1996 to February 1998. (Dmi = D. minutus; Dna $=D$. nanus $;$ Dsa $=D$ sanborn $;$ Del $=D$. elianae $; \mathrm{Hca}=H$. caingua $;$ $\mathrm{Hal}=H$. albopunctatus $; \mathrm{Sfu}=$ Scinax fuscovariu $; \mathrm{Cic}=$ Chaunus ictericus $;$ $\mathrm{Pcu}=$ Physalaemus cuvieri $;$ Loc $=$ Leptodactylus ocellatus $).$

Os hilídeos de hábito trepador apresentaram grande variação intrapopulacional na altura média de empoleiramento (Tabela 3). Apesar disso, houve diferença entre D. minutus e D. nanus $(\mathrm{t}=5,99$, $\mathrm{p}<0,05)$; D. minutus e D. sanborni $(\mathrm{t}=2,99, \mathrm{p}<0,05)$ e $D$. minutus e $H$. albopunctatus $(\mathrm{t}=3,36, \mathrm{p}<0,05)$. Houve uma tendência das espécies de hilídeos de hábito trepador ocuparem sítios de vocalização mais baixos nos meses mais frios e com índices pluviométricos menores (Figura 3); com exceção de D. elianeae, os hilídeos de pequeno porte ocorreram externamente à margem da poça somente nos meses com altos índices pluviométricos (Figura 3).

A única espécie intermediária na ocupação do estrato vertical e generalista na ocupação do estrato horizontal foi $D$. nanus. As demais espécies foram especialistas para estas duas dimensões do sítio de vocalização (Tabela 3). A análise de agrupamento evidenciou três guildas de anuros, cujas espécies apresentaram alta sobreposição na ocupação de sítios de vocalização (Tabela 4 e Figura 6):

1) Dendropsophus nanus, D. sanborni, H. albopunctatus e $H$. caingua, cujos machos vocalizaram empoleirados na vegetação;

2) Scinax fuscovarius, C. ictericus e D. minutus, cujos machos vocalizaram sobre o solo; e

3) P. cuvieri e L. ocellatus, cujos machos vocalizaram flutuando na superfície ou apoiados no fundo do corpo d'água.

Dentre as 45 combinações possíveis de pares de espécies, $10(22,2 \%)$ apresentaram alta sobreposição $\left(\mathrm{C}_{\mathrm{H}}>0,71\right.$, Tabela 4$)$. 
Tabela 2. Sobreposição sazonal entre as 12 espécies de anuros registradas em uma poça permanente em Rubião Jr., Botucatu, SP amostrada entre outubro de 1996 e fevereiro de 1998 (abreviações como nas figuras anteriores).

Table 2. Seasonal overlapping among the 12 anurans species registered in a permanent pond in Rubião Jr, Botucatu, SP, sampled between October 1996 and February 1998 (abbreviations as in the previous figures).

\begin{tabular}{|c|c|c|c|c|c|c|c|c|c|c|c|c|}
\hline & Dmi & Dna & Dsa & Del & Hca & Hal & Hfa & Sfu & Cic & Pcu & Loc & Lla \\
\hline Dmi & - & - & - & - & - & - & - & - & - & - & - & - \\
\hline Dna & 0,58 & - & - & - & - & - & - & - & - & - & - & - \\
\hline Das & 0,65 & 0,47 & - & - & - & - & - & - & - & - & - & - \\
\hline Del & 0,42 & 0,79 & 0,37 & - & - & - & - & - & - & - & - & - \\
\hline Hca & 0,30 & 0,00 & 0,06 & 0,00 & - & - & - & - & - & - & - & - \\
\hline Hal & 0,56 & 0,09 & 0,63 & 0,00 & 0,32 & - & - & - & - & - & - & - \\
\hline Hfa & 0,27 & 0,09 & 0,26 & 0,16 & 0,00 & 0,42 & - & - & - & - & - & - \\
\hline Sfu & 0,31 & 0,54 & 0,63 & 0,60 & 0,00 & 0,02 & 0,00 & - & - & - & - & - \\
\hline Cic & 0,56 & 0,50 & 0,61 & 0,49 & 0,02 & 0,35 & 0,10 & 0,42 & - & - & - & - \\
\hline $\mathrm{Pcu}$ & 0,69 & 0,84 & 0,65 & 0,68 & 0,01 & 0,14 & 0,25 & 0,61 & 0,56 & - & - & - \\
\hline Loc & 0.59 & 0,53 & 0,73 & 0,50 & 0,00 & 0,30 & 0,53 & 0,57 & 0,40 & 0,73 & - & - \\
\hline Lla & 0,16 & 0,20 & 0,26 & 0,32 & 0,00 & 0.00 & 0,40 & 0,26 & 0,26 & 0,40 & 0,53 & - \\
\hline
\end{tabular}

Tabela 3. Distribuição vertical e horizontal (média \pm desvio padrão) e valores de amplitude de nicho nestas duas dimensões para as espécies registradas em uma poça permanente em Rubião Jr., Botucatu, SP. (B = índice de Levins; valores negativos indicam localização externa ao corpo d'água).

Table 3. Vertical and horizontal distribution (average \pm standard deviation) and values of niche breadth in these two dimensions for the species registered in a permanent pond in Rubião Jr, Botucatu, SP. (B = index of Levins; negative values indicate external localization in the water body).

\begin{tabular}{lcccc}
\hline & Dist. Vert & Dist. Hor & B-vert & B-hor \\
\hline D. minutus & $11,8 \pm 15,5$ & $41,9 \pm 75,4$ & 0,1 & 0,27 \\
D. nanus & $29,9 \pm 19,1$ & $-17,5 \pm 65,5$ & $0,58(*)$ & $0,73(*)$ \\
D. sanborni & $23,4 \pm 13,4$ & $38,8 \pm 54$ & 0,34 & 0,2 \\
D. elianeae & $34,7 \pm 24,4$ & $-23,0 \pm 110$ & 0,22 & 0,06 \\
H. albopunctatus & $29,8 \pm 23,5$ & $-56,6 \pm 147,9$ & 0,47 & 0,42 \\
H. caingua & $20,5 \pm 15,1$ & $-17,0 \pm 144,9$ & 0,36 & 0,37 \\
H. prasinus & - & - & - & - \\
H. faber & - & - & - & - \\
S. fuscovarius & 0,0 & $-26,5 \pm 51,1$ & 0 & 0,09 \\
P. cuvieri & $3,4 \pm 3,0$ & $7,41 \pm 55,5$ & 0,08 & 0,04 \\
E. nattereri & - & - & - & - \\
C. ictericus & 0,0 & $29,3 \pm 89,1$ & 0 & 0,27 \\
L. ocellatus & $6,67 \pm 3,3$ & 110 & 0 & - \\
L. labyrinthicus & - & - & - & 0,06 \\
\hline
\end{tabular}

\section{Nicho multidimensional}

A análise de agrupamento para as dimensões tempo e sítio de vocalização evidenciou quatro guildas de espécies com sobreposição em ambas as dimensões do nicho (Figura 7):

1) P. cuvieri e L. ocellatus;

2) D. nanus e D. elianeae;

3) D. minutus, S. fuscovarius e C. ictericus; e

4) D. sanborni e H. albopunctatus.

Das 45 combinações possíveis de pares de espécies, apenas três $(6,7 \%)$ apresentaram alta sobreposição $\left(\mathrm{C}_{\mathrm{H}}>0,71\right)$, sendo que em 27 $(60 \%)$ dos pares de espécies os valores de sobreposição foram baixos $\left(\mathrm{C}_{\mathrm{H}}<0,50\right.$, Tabela 5).

\section{Discussão}

O padrão de distribuição sazonal observado para a comunidade de anuros estudada corresponde ao descrito por outros autores para a região neotropical (e.g. Pombal Jr. 1997), ainda que o ambiente em estudo esteja localizado em área muito alterada pelo homem. A riqueza de espécies foi menor nos meses mais frios; nesses meses, ainda que a pluviosidade aumentasse para valores superiores àqueles de alguns meses da estação quente e úmida $\left(100 \mathrm{~mm}^{3}\right)$, a riqueza de espécies não aumentou. Isto pode explicar o fato que, embora significativo, o valor de correlação entre a riqueza e a pluviosidade não tenha sido alto. Além disso, dentre as oito espécies para as quais foi possível realizar a análise de correlação, quatro apresentaram abun- 

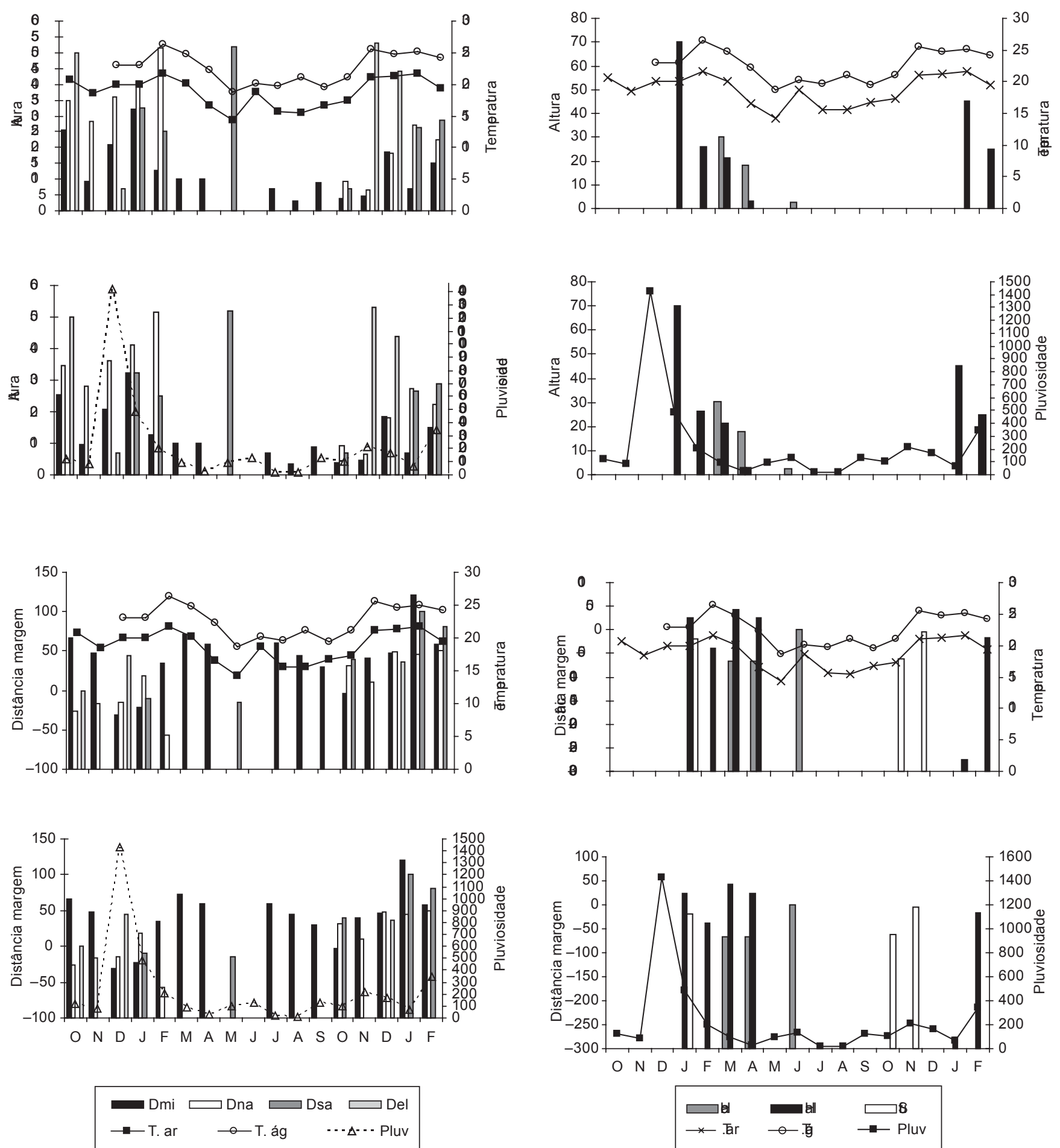

Figura 3. Médias mensais de temperatura $\left({ }^{\circ} \mathrm{C}\right)$ e total mensal de precipitação $\left(\mathrm{mm}^{3}\right)$ e valores médios mensais de altura e distância da margem ocupadas pelos hilídeos de pequeno porte em uma poça permanente em Rubião Jr., Botucatu, São Paulo. Sinais negativos indicam sítio de vocalização externo ao corpo d'água. $($ Dmi $=$ Dendropsophus minutus, $\mathrm{Dna}=D$. nanus, Dsa $=$ D. sanborni, Del $=$ D. elianeae $)$.

Figure 3. Monthly averages of temperature $\left({ }^{\circ} \mathrm{C}\right)$ and rainfall $\left(\mathrm{mm}^{3}\right)$ and monthly average values of height and distance from the edge for the small hylids in a permanent pond in Rubião Jr, Botucatu, São Paulo. Negative signals indicate calling sites external to the water body. (Dmi = Dendropsophus minutus, Dna $=$ D. nanus, Dsa $=S$. sanborni, Del $=D$. elianeae $)$

Figura 4. Médias mensais de temperatura $\left({ }^{\circ} \mathrm{C}\right)$ e total mensal de precipitação $\left(\mathrm{mm}^{3}\right)$ e valores médios mensais de altura e distância da margem ocupadas pelos hilídeos de maior porte em uma poça permanente em Rubião Jr., Botucatu, São Paulo. (Hca = Hypsiboas caingua, $\mathrm{Hal}=H$. albopunctata, $\mathrm{Sfu}=$ Scinax fuscovarius).

Figure 4. Monthly averages of temperature $\left({ }^{\circ} \mathrm{C}\right)$ and rainfall $\left(\mathrm{mm}^{3}\right)$ and monthly average values of height and distance from the edge for the larger hylids in a permanent pond in Rubião Jr, Botucatu, São Paulo. ( Hca = Hypsiboas caingua, $\mathrm{Hal}=$ H. albopunctatus, $\mathrm{Sfu}=$ Scinax fuscovarius $)$. 

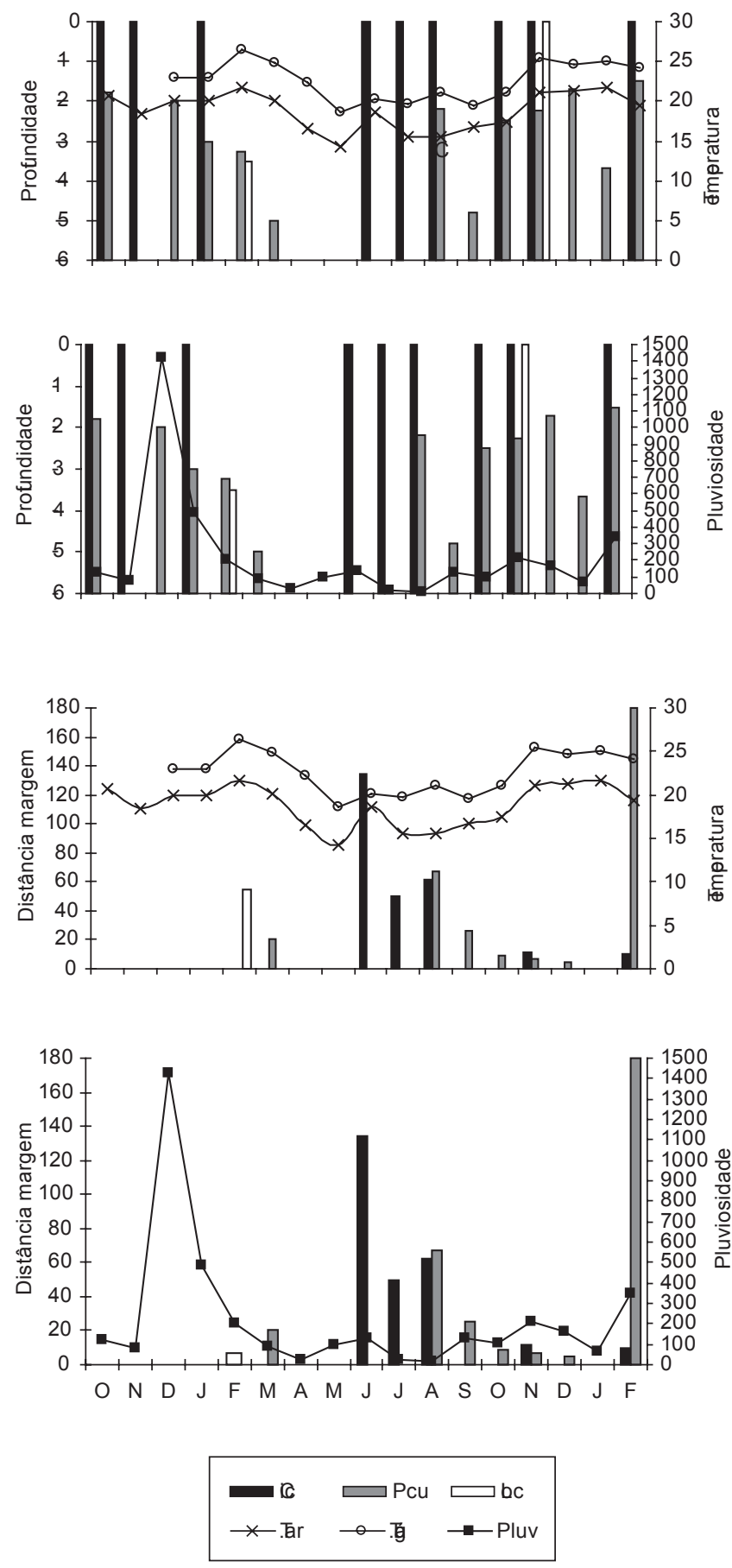

Figura 5. Médias mensais de temperatura $\left({ }^{\circ} \mathrm{C}\right)$ e total mensal de precipitação $\left(\mathrm{mm}^{3}\right)$ e valores médios mensais de altura e distância da margem ocupadas por Chaunus ictericus (Cic), Physalaemus. cuvieri (Pcu) e Leptodactylus ocellatus (Loc) na poça permanente em Rubião Jr., Botucatu, São Paulo.

Figure 5. Monthly averages of temperature $\left({ }^{\circ} \mathrm{C}\right)$ and rainfall $\left(\mathrm{mm}^{3}\right)$ and monthly average values of height and distance from the edge for Chaunus ictericus (Cic), Physalaemus cuvieri (Pcu) and Leptodactylus ocellatus (Loc) in the permanent pond in Rubião Jr, Botucatu, São Paulo.

dância correlacionada com as temperaturas do ar e da água; porém dentre elas, somente duas (Dendropsophus nanus e D. sanborni) tiveram a abundância correlacionada também com a pluviosidade. Em estudo desenvolvido em uma região de clima mais quente e seco (Vasconcelos \& Rossa-Feres 2005) e em outro desenvolvido em região de clima semelhante ao de Botucatu (Toledo et al., 2003), independentemente do tipo e tamanho dos corpos d'água observados, o número de espécies em atividade de vocalização foi influenciado pela pluviosidade e pelas temperaturas médias mensais. Resultado semelhante foi encontrado por Prado et al. (2005) na região do Pantanal, Centro-Oeste do Brasil. De acordo com Nimer (1979), a região sudeste do Brasil é uma região de transição entre os climas quentes das latitudes baixas e os climas mesotérmicos das latitudes médias, apresentando notável diversidade climática. Deste modo e, conforme discutido por Jim (2002), a região de Botucatu pode ser caracterizada como uma "ilha" de temperaturas mais baixas e umidade elevada. Assim, havendo maior umidade ao longo de todo o ano, é provável que a ocorrência de chuvas não exerça grande influência na variação de abundância das espécies nesta região, possibilitando, ainda, a presença de espécies adaptadas a temperaturas mais baixas, como é o caso de $H$. caingua.

O clima mais úmido da região de Botucatu, quando comparado a outras regiões do Estado de São Paulo, exceto áreas de mata atlântica (eg. Heyer et al. 1990), possibilita a ocorrência de anuros na estação fria e seca ampliando as possibilidades de partilha sazonal entre as espécies. Entretanto, os menores valores de sobreposição sazonal foram observados entre espécies pouco abundantes, como Dendropsophus elianeae, Hypsiboas faber e H. albopunctatus, ou com ocorrência explosiva (sensu Wells, 1977), como é o caso de Scinax fuscovarius. A presença de espécies acidentais ou raras em cada guilda, o padrão sucessional na distribuição das espécies e o fato de que, exceto Dendropsophus minutus, todas as demais espécies foram especialistas quanto à ocorrência sazonal, foram os fatores que contribuíram para a partilha sazonal dos anuros nesta comunidade.

A tendência observada entre os hilídeos que vocalizaram empoleirados, principalmente os de pequeno porte, de ocuparem sítios de vocalização diferentes em função da temperatura e da pluviosidade, indica que o uso de sítio de vocalização varia em uma mesma estação. A distribuição vertical variou mais em função da temperatura provavelmente porque, próxima ao solo ou ao corpo d'água a temperatura é um pouco mais alta. Do mesmo modo, a distribuição horizontal das espécies menores de hilídeos variou mais em função da pluviosidade: anfíbios pequenos possuem, proporcionalmente, mais área de superfície que anfíbios maiores e, portanto, têm uma maior taxa de perda de água por evaporação (Duellman \& Trueb 1994), o que explica o fato dessas espécies terem ocorrido externamente ao corpo d'água somente nos meses com altos índices pluviométricos.

De modo geral, os hilídeos de pequeno porte ocorreram no interior da poça, os hilídeos maiores de hábito trepador ocorreram externamente à poça e as espécies terrestres ou de hábito semi-aquático ocorreram na margem. Isto pode decorrer de restrições de tamanho, fisiológica ou filogenética. Por outro lado, a presença de grande número de espécies especialistas no uso de sítio de vocalização não evitou a ocorrência de sobreposição entre elas.

Segundo Faivovich et al. (2005) as espécies aqui denominadas hilídeos de pequeno porte (todas do gênero Dendropsophus) são filogeneticamente mais próximas entre si; Hypsiboas caingua e $H$. albopunctatus são filogeneticamente mais próximas entre si do que com qualquer das outras espécies aqui estudadas. Isto aponta para a forte influência de restrições filogenéticas nos caracteres ecológicos dos anuros.

Apesar de Dendropsophus sanborni ter seu período de ocorrência incluído no de D. nanus, não houve sobreposição entre elas, principalmente devido ao fato de que a abundância de $D$. sanborni foi bem menor e pareceu variar mais em função da abundância da primeira que da temperatura ou pluviosidade. Entretanto, tais espécies apre- 
Tabela 4. Sobreposição de sítio de vocalização entre 10 espécies de anuros mais abundantes registradas em uma poça permanente em Rubião Jr., Botucatu, SP amostrada entre outubro de 1996 e fevereiro de 1998 (abreviações como nas figuras anteriores).

Table 4. Overlap of calling sites among the 10 more abundant species registered in a permanent pond in Rubião Jr, Botucatu, SP, sampled between October 1996 and February 1998 (abbreviations as in the previous figures).

\begin{tabular}{|c|c|c|c|c|c|c|c|c|c|c|}
\hline & Dmi & Dna & Dsa & Del & Hca & Hal & Sfu & Cic & Pcu & Loc \\
\hline Dmi & - & - & - & - & - & - & - & - & - & - \\
\hline Dna & 0,69 & - & - & - & - & - & - & - & - & - \\
\hline Dsa & 0,64 & 0,86 & - & - & - & - & - & - & - & - \\
\hline Del & 0,49 & 0,55 & 0,46 & - & - & - & - & - & - & - \\
\hline Hca & 0,72 & 0,79 & 0,69 & 0,39 & - & - & - & - & - & - \\
\hline Hal & 0,72 & 0,84 & 0,69 & 0,54 & 0,74 & - & - & - & - & - \\
\hline $\mathrm{Sfu}$ & 0,84 & 0,41 & 0,32 & 0,35 & 0,55 & 0,50 & - & - & - & - \\
\hline Cic & 0,93 & 0,49 & 0,41 & 0,40 & 0,57 & 0,59 & 0,93 & - & - & - \\
\hline $\mathrm{Pcu}$ & 0,25 & 0,26 & 0,34 & 0,50 & 0,19 & 0,16 & 0,15 & 0,15 & - & - \\
\hline Loc & 0,63 & 0,45 & 0,46 & 0,59 & 0,39 & 0,36 & 0,51 & 0,61 & 0,82 & - \\
\hline
\end{tabular}

Tabela 5. Sobreposição de nicho multidimensional entre 10 espécies de anuros mais abundantes registradas em uma poça permanente em Rubião Jr., Botucatu, SP amostrada entre outubro de 1996 e fevereiro de 1998 (abreviações como nas figuras anteriores).

Table 5. Overlap of multidimensional niche among the 10 more abundant species registered in a permanent pond in Rubião Jr, Botucatu, SP, sampled between October 1996 and February 1998 (abbreviations as in the previous figures).

\begin{tabular}{|c|c|c|c|c|c|c|c|c|c|c|}
\hline & Dmi & Dna & Dsa & Del & Hca & Hal & Sfu & Cic & Pcu & Loc \\
\hline Dmi & - & - & - & - & - & - & - & - & - & - \\
\hline Dna & 0,43 & - & - & - & - & - & - & - & - & - \\
\hline Dsa & 0,62 & 0,47 & - & - & - & - & - & - & - & - \\
\hline Del & 0,46 & 0,64 & 0,41 & - & - & - & - & - & - & - \\
\hline Hca & 0,61 & 0,14 & 0,37 & 0,22 & - & - & - & - & - & - \\
\hline Hal & 0,66 & 0,19 & 0,67 & 0,27 & 0,51 & - & - & - & - & - \\
\hline Sfu & 0,69 & 0,39 & 0,42 & 0,43 & 0,38 & 0,31 & - & - & - & - \\
\hline $\mathrm{Cic}$ & 0,80 & 0,35 & 0,52 & 0,42 & 0,38 & 0,52 & 0,74 & - & - & - \\
\hline $\mathrm{Pcu}$ & 0,34 & 0,44 & 0,43 & 0,55 & 0,15 & 0,16 & 0,27 & 0,24 & - & - \\
\hline Loc & 0,62 & 0,38 & 0,55 & 0,55 & 0,26 & 0,24 & 0,53 & 0,54 & 0,80 & - \\
\hline
\end{tabular}

sentaram grande similaridade no sítio de vocalização. Em um estudo em três diferentes açudes na região noroeste do Estado de São Paulo, Menin et al. (2005) também registraram grande similaridade no sítio de vocalização de $D$. nanus e $D$. sanborni, o que pode ser reflexo da história evolutiva dessas duas espécies taxonomicamente próximas, já que, padrão semelhante de interação na ocorrência temporal e no uso de micro-ambientes foi registrado em diferentes regiões e em corpos d'água de tamanhos diferentes. Thompson (1994) afirma que as interações entre espécies são formadas, em parte, pela bagagem filogenética da fisiologia e comportamento que os organismos herdam de seus ancestrais.

Macnally (1985) encontrou sobreposição de microhábitat em duas espécies de Crinia na Austrália, mas que apresentaram segregação sazonal. Begon et al. (1990) afirmam que ocorre complementaridade de nicho quando a diferenciação de nicho, dentro de uma guilda, envolve várias dimensões do nicho e as espécies que ocupam uma posição semelhante ao longo de uma dimensão tendem a diferir ao longo de outra.

As espécies de anuros estudadas em um açude temporário na região noroeste do Estado de São Paulo por Rossa-Feres \& Jim (2001) também apresentaram sobreposição espacial, mas com partilha no espaço acústico. Diferentemente do presente estudo, os autores encontraram um maior número de espécies generalistas para sítio de vocalização. Tal diferença pode ser devido ao fato do corpo d'água presentemente amostrado ser permanente. Segundo Putman (1994) em ambientes onde as condições e a disponibilidade de recursos são imprevisíveis e variáveis, nenhum organismo pode tornar-se demasiadamente especialista.

No presente estudo, todos os pares de espécies que apresentaram sobreposição no sítio de vocalização, apresentaram partilha sazonal; a única exceção foi o par $P$. cuvieri - L. ocellatus, que apresentaram tanto sobreposição sazonal quanto espacial. No entanto, neste caso, L. ocellatus foi pouco abundante e pouco freqüente.

De modo geral, a sobreposição multidimensional foi intermediária entre a sobreposição sazonal que foi, em geral, menor e a sobreposição no sítio de vocalização que foi, em geral, maior, demonstrando complementaridade de nicho. Apenas a guilda formada por D. nanus e D. elianeae apresentou alta sobreposição temporal; as demais espécies apresentaram alta sobreposição no uso de sítio de vocalização. Assim, na comunidade estudada em Rubião Jr. a partilha no nicho multidimensional foi claramente possível pela grande partilha na distribuição temporal das espécies. Embora muitos autores tenham apontado a partilha de hábitat como um dos principais fatores que permitem a coexistência das espécies em uma comunidade (e.g. Schoener 1974; Rosenzweig 1981; Wiest 1982), provavelmente esta dimensão do nicho desempenha papel fundamental somente em locais onde a possibilidade de partilha sazonal seja pequena, como em corpos de água temporários 


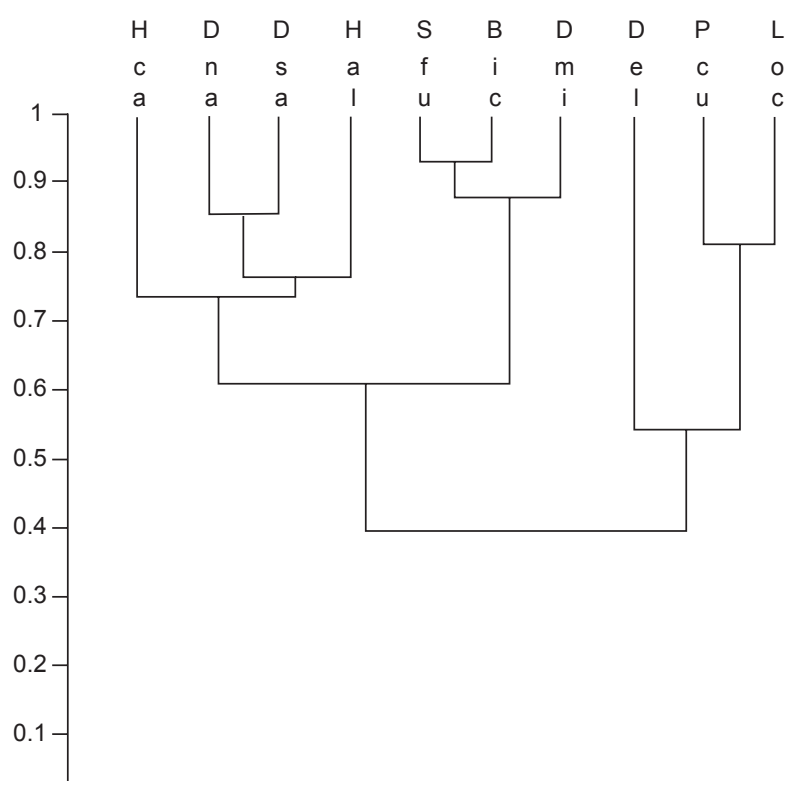

Figura 6. Similaridade (índice de Morisita-Horn) no uso de sítio de vocalização (posição vertical e horizontal) de 10 espécies de anuros registradas em uma poça permanente em Rubião Jr., Botucatu, SP, amostrada no período de outubro de 1996 a fevereiro de 1998 (abreviações como na Figura 5).

Figure 6. Similarity (Morisita-Horn index) in the use of calling sites (vertical and horizontal position) of 10 species of anurans registered in a permanent pond in Rubião Jr, Botucatu, SP, sampled from October 1996 to February 1998 (abbreviations as in Figure 5).

ou em regiões com estação seca pronunciada e estação chuvosa com índices pluviométricos mais baixos (e.g. Vasconcelos \& Rossa-Feres, 2005; Rossa-Feres \& Jim, 2001). Em corpos d'água permanentes, onde há uma sucessão na ocorrência das espécies ao longo do ano, a partilha microespacial pode exercer papel secundário em evitar a sobreposição no uso de sítios reprodutivos e, inclusive, sítios de forrageamento.

\section{Agradecimentos}

Ao Sr. Nelson Carneiro pelo valioso auxílio nas atividades de campo. Ao Dr. Benedito Rinaldo Cardana pelo auxílio na diferenciação dos exemplares de Dendropsophus nanus e D. sanborni, na tomada das medidas e proporções da área de estudo e nas atividades de campo. Aos dois assessores anônimos da revista Biota Neotropica pelas correções e valiosas sugestões. Esse trabalho foi parcialmente financiado pela FAPESP (Programa Biota/FAPESP, Proc. no. 01/13341-3). Ao CNPq pela bolsa concedida ao primeiro autor.

\section{Referências Bibliográficas}

AICHINGER, M. 1987. Annual activity patterns of anurans in a seasonal neotropical environment. Oecologia 71:583-592.

BEGON, M., HARPER, J.L., TOWNSEND, C.R. 1990. Ecology. 2ed. Blackwell Scientific Publications, Boston.

BERTOLUCI, J. 1998. Annual patterns of breeding activity in Atlantic rainforest anurans. J. Herpetol. 32(4):607-611.

CARDOSO, A.J., ANDRADE, G.V. \& HADDAD, C.F.B. 1989. Distribuição espacial em comunidades de anfíbios (Anura) no sudeste do Brasil. Rev. Bras. Biol. 49(1):241-249.

CONTE, C.E. \& ROSSA-FERES, D.C. 2006. Diversidade e ocorrência temporal da anurofauna (Amphibia, Anura) em São José dos Pinhais, Paraná, Brasil. Rev. Bras. Zool. 23(1):162-175.

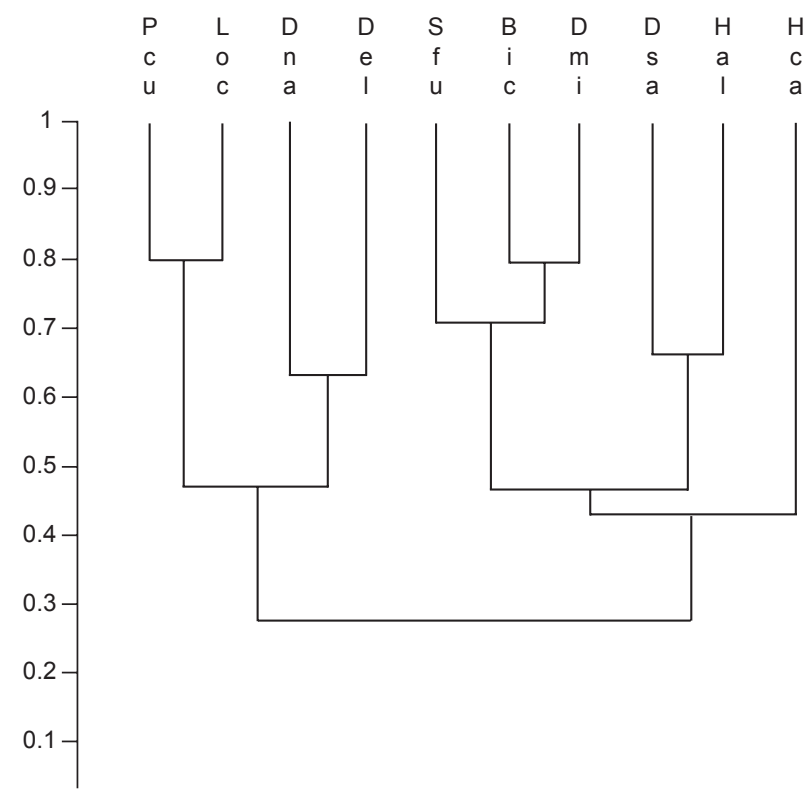

Figura 7. Similaridade (índice de Morisita-Horn) na ocorrência sazonal e sítio de vocalização de 10 espécies de anuros registradas na poça permanente em Rubião Jr., Botucatu, SP, amostrada no período de outubro de 1996 a fevereiro de 1998 (abreviações como na Figura 5).

Figure 7. Similarity (Morisita-Horn index) in the seasonal occurrence and calling sites of 10 species of anurans registered in the permanent pond in Rubião Jr, Botucatu, SP, sampled from October 1996 to February 1998 (abbreviations as in the Figure 5).

CRUMP, M.L. 1971. Quantitative analysis of the ecological distribution of a tropical herpetofauna. Occ. Pap. Mus. Nat. Hist. Univ. Kansas 3:1-62.

DAJOZ, R. 1973. Ecologia Geral. 2ed. Editora Vozes, São Paulo.

DONNELLY, M. A., GUYER, C. 1994. Patterns of reproduction and habitat use in an assemblage of neotropical hylid frogs. Oecologia, 98 (3-4): 291-302.

DUELLMAN, W.E. \& TRUEB, L. 1994. Biology of Amphibians. The Johns Hopkins University Press, Baltimore.

ETEROVICK, P.C. \& SAZIMA, I. 2000. Structure of an anuran community in a montane meadow in southeastern Brazil: effects of seasonality, habitat, and predation. Amphibia-Reptilia 21:439-461.

FAIVOVICH, J., HADDAD, C.F.B., GARCIA, P.C.A., FROST,D.R., CAMPBELL,J.A. \& WHEELER, W.C. 2005. Systematic review of the frog family Hylidae, with special reference to Hylinae: phylogenetic analysis and taxonomic revision. Bull. Am. Mus. Nat. Hist (294):1-240.

GASCON, C. 1991. Population-and community-level analyses of species occurrences of Central Amazonian Rainforest tadpoles. Ecology 72(5):1731-1746

HADDAD, C.F.B. \& SAZIMA, I. 1992. Anfíbios anuros da Serra do Japi. In: História natural da Serra do Japi: ecologia e preservação de uma área florestal no sudeste do Brasil. (L.P.C. Morellato, org.). Unicamp. Campinas, p.188-211.

HEYER, W. R., RAND, A.S., CRUZ, C.A.G., PEIXOTO, O.L. \& NELSON, C.E. 1990. Frogs of Boracéia. Arquivos de Zoologia, São Paulo, 31(4):231-410.

JIM, J. 2002. Variação altitudinal e estudo de longa duração de anfíbios da região de Botucatu, Estado de São Paulo. Tese de Livre-Docência, Instituto de Biociências de Botucatu, Universidade Estadual Paulista.

KREBS, C. J. Ecological methodology. 1999. Addison Wesley Educational Publishers. Menlo Park. 
KRONKA, F.J.N., NALON, M.A. \& MATSUKUMA, C.K. 1998. Áreas de dominio de Cerrado no Estado de São Paulo. Secretaria do Meio Ambiente, São Paulo.

MacNALLY, R.C. 1985. Habitat and microhabitat distributions in relation to ecological overlap in two species of Ranidella (Anura). Aust. J. Zool. 33:329-338.

MENIN, M., ROSSA-FERES, D.C. \& GIARETTA, A.A. 2005. Resource use and coexistence of two syntopic hylid frogs (Anura, Hylidae). Rev. Bras. Zool. 22(1):61-72.

MORRIS, D.W., 1990. Temporal variation, habitat selection and community structure. Oikos 59:303-312.

NECKEL-OLIVEIRA, S., MAGNUSSOM, W.E., LIMA, A.P. \& ALBERNAZ, A.L.K. 2000. Diversity and distribution of frogs in an Amazonian savanna in Brazil. Amphibia-Reptilia 21:317-326.

NIMER, E. 1979. Climatologia do Brasil. Secretaria de Planejamento da Presidência da República, IBGE, série Recursos Naturais e Meio Ambiente (4), Rio de Janeiro.

POMBAL JR., J.P. 1997. Distribuição espacial e temporal de anuros (Amphibia) em uma poça permanente na Serra de Paranapiacaba, Sudeste do Brasil. Rev. Bras. Biol. 57(2):583-594.

PRADO, C.P.A., UETANABARO, M. \& HADDAD, C.F.B. 2005. Breeding activity patterns, reproductive modes, and habitat use by anurans (Amphibia) in a seasonal environment in the Pantanal, Brazil. AmphibiaReptilia 26(2005):211-221.

PUTMAN, R. J. 1994. Community ecology. Chapman \&Hall, London.

ROSENZWEIG, M.L. 1981. A theory of habitat selection. Ecology 62 (2):27-225
ROSSA-FERES, D. de C. \& JIM, J. 1994. Distribuição sazonal em comunidades de anfíbios anuros na região de Botucatu, São Paulo. Rev. Bras. Biol. 54:323-334.

ROSSA-FERES, D. de C. \& JIM, J. 2001. Similaridade do sítio de vocalização em uma comunidade de anfíbios anuros na região noroeste do Estado de São Paulo, Brasil. Rev. Bras. Zool. 18(2):439-454.

SCHOENER, T.W. 1974. Resource partitioning in ecological communities. Science 185:7-39.

THOMPSON, J.N. 1994. The coevolutionary Process. The University of Chicago press, Chicago.

TOLEDO, L.F. \& HADDAD, C.F.B. 2003. Distribuição espacial e temporal de uma comunidade de anfíbios anuros do município de Rio Claro, São Paulo, Brasil. Holos Environment 3(2):136-149.

VASCONCELOS, T.S. \& ROSSA-FERES, D.C. 2005. Diversidade, distribuição espacial e temporal de anfíbios anuros (Amphibia, Anura) na região Noroeste do Estado de São Paulo, Brasil. Biota Neotrop. 5(2) http. www.biotaneotropica.org.br/v5n2/pt/abstract?article+BN0170522005.

VIEIRA, S. 1985. Introdução à Bioestatística. 3 ed. Campus, Rio de Janeiro.

WELLS, K.D. 1977. The social behaviour of anuran amphibians. Animal Behaviour 25(3):666-693.

WIEST-JR, J.A. 1982. Anuran succession at temporary ponds in a post oaksavana region of Texas. In Herpetological communities (N.J. Scott Jr., ed), United States Department of the Interior, Wildl. Res. Rep 13:39-47. Washington, D. C. 